\title{
Lawrence, 1912: Fake news about real evils
}

\author{
Peter G. Doyle \\ Version 1.0 dated 29 July 2019 \\ No Copyright*
}

\begin{abstract}
In a speech in Lawrence, Massachusetts on 9 February 2019, Elizabeth Warren stated that at the time of the 1912 Lawrence millworkers' strike, 'One out of every three adult mill workers died by the time they were 25.' Where did this statistic come from?
\end{abstract}

\section{An unbelievable statistic.}

\subsection{Warren (2019).}

Elizabeth Warren, Official presidential campaign announcement, Lawrence, Mass., 9 Feb 2019:

A little over 100 years ago, the textile mills in Lawrence employed tens of thousands of people, including immigrants from more than 50 countries.

Business was booming. The guys at the top were doing great. But workers made so little money that families were forced to crowd together in dangerous tenements and live on beans and scraps of bread. Inside the mills, working conditions were horrible. Children were forced to operate dangerous equipment. Workers lost hands, arms, and legs in the gears of machines.

One out of every three adult mill workers died by the time they were 25 .

${ }^{*}$ The author(s) hereby waive all copyright and related or neighboring rights to this work, and dedicate it to the public domain. This applies worldwide. 
Where did this statistic come from? No source is cited; the Wikipedia is an obvious suspect.

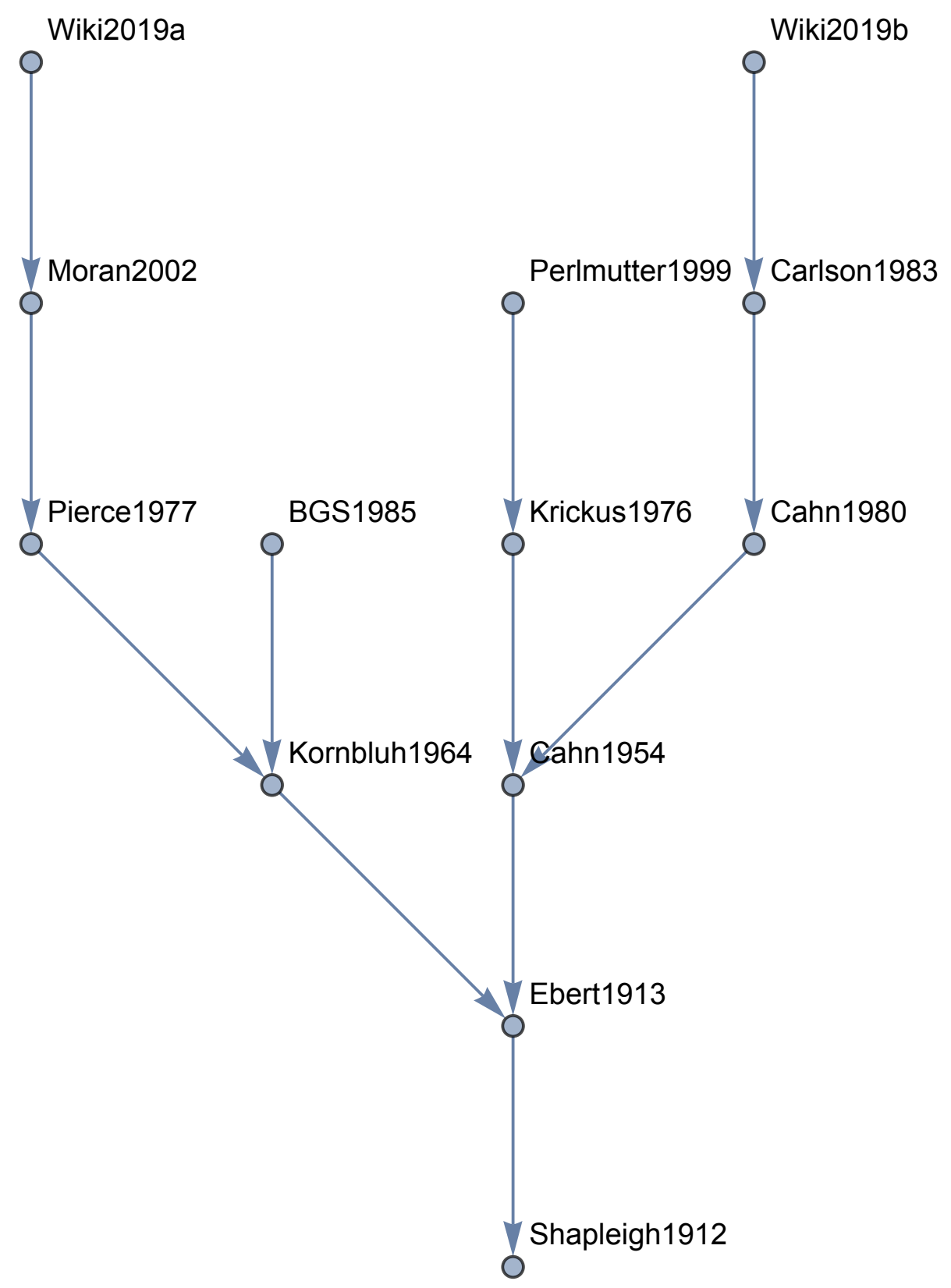




\subsection{Wikipedia (2019a).}

Wikipedia, '1912 Lawrence textile strike,' retrieved 9 February 2019:

Half of children died before they were six, and $36 \%$ of the adults who worked in the mill died before they were 25 . The average life expectancy was 39. [Footnote: Moran, William (2002). ... Elizabeth Shapleigh, a physician in the city, made a mortality study among mill workers and found that onethird of them, victims of the lint-filled air of the mills, died before reaching the age of 25 .]

Cites Moran (2002).

\subsection{Moran (2002).}

William Moran, The Belles of New England: The Women of the Textile Mills and the Families Whose Wealth They Wove, Macmillan, 2002, p. 183:

Many other children worked in the Lawrence mills. In 1911, the year before Camella Teoli's testimony, four hundred children had quit grammar school, and 70 percent of them entered the mills. Only the robust lasted. Elizabeth Shapleigh, a physician in the city, made a mortality study among mill workers and found that one-third of them, victims of the lint-filled air of the mills, died before reaching the age of twenty-five. "Every fourth person in line is dying from tuberculosis," she said. "And further, every second person, that is, one alternating with a healthy person, will die of some form of respiratory trouble."

Cites Pierce (1977).

\subsection{Pierce (1977).}

Edward F. Pierce, Jr., The Lawrence Textile Strike of 1912 And the Role Of The Industrial Workers of the World, masters thesis, Southern Connecticut State College, 15 November 1977, p. 17:

Pneumonia, tuberculosis, and respiratory infections killed 70 percent of the textile operatives and only 4 percent of the farmers in the Lawrence area. Mill operatives had the shortest average 
life span, 39.6 years, of an other occupation in the city. Doctor Shapleigh, a Lawrence resident who studied the subject said,

\author{
36 out of every 100 of all the men and women \\ who work in the mills die before, or by the time, \\ they are 25 years of age. That means that out \\ of the long line which enters the mill you may \\ strike out every third person as dying before \\ reaching maturity. Every fourth person in line \\ is dying from tuberculosis. And further, every second \\ person, that is one alternating with a healthy person, \\ will die of some form of respiratory trouble.
}

Cites Ebert in Kornbluh (1964).

\title{
1.5 Kornbluh (1964).
}

Rebel Voices: An I.W.W. Anthology, edited, with introductions, by Joyce L. Kornbluh, University of Michigan Press, 1964, p. 169:

Reprints Ebert (1913) verbatim.

\subsection{Ebert (1913).}

Justus Ebert, The Trial of a New Society - Being a Review of The Celebrated Ettor-Giovannitti-Caruso Case, Beginning with the Lawrence Textile Strike that caused it and including the general strike that grew out of it, I. W. W. Publishing Bureau, Cleveland, Ohio, 1913, p. 25:

In the matter of longevity, according to Lawrence's mortuary records, its lawyers and clergymen lead, with an average length of life of 65.4 years. Manufacturers come next with 58.5 years; farmers follow with 57 years. From the mortality records of 1,010 operatives, the average length of life was found to be 39.6 years. The average longevity for spinners is three and two-fifths years less, or 36 years. On an average, the spinner's life is 29 years less than that of the lawyer's or clergyman's and 22.5 year years shorter than that of the manufacturer. [15: Dr. Elizabeth Shapleigh, Occupational Diseases in the Textile Industry. New York Call, Dec. 29, 1912.] 
Says Dr. Shapleigh, a Lawrence practitioner, who made a special study of the subject: "36 out of every 100 of all the men and women who work in the mill die before, or by the time, they are 25 years of age. That means that out of the long line which enters the mill you may strike out every third person as dying before reaching maturity. Every fourth person in the line as dying from tuberculosis. And further, every second person, that is one alternating with a healthy person, will die of some form of respiratory trouble." The same authority states that "a considerable number of the boys and girls die within the first two or three years after beginning work." [16. Ibid.] So poorly are they nourished and developed, that they have not the stamina to withstand the strain.

Cites Shapleigh (1912).

\subsection{Shapleigh (1912).}

Elizabeth Shapleigh, M.D., Occupational diseases in the textile industry, The New York Call, Sunday 29 December 1912, p. 13:

'Of all those persons engaged in spinning as a trade, 36.6 per cent die before they have worked ten years. Out of a hundred deaths thirty-six die before they are 25 years of age, and fifty-two before they are 35 years of age. That is, over one-third die just as they attain maturity, and over onehalf as they reach the most productive years.'

See Appendix A for the full text of Shapleigh's article.

\section{An alternate path.}

An alternate path back to Shapleigh leads from the Wikipedia article on Anna LoPizzo.

\subsection{Wikipedia (2019b).}

Wikipedia, 'Anna LoPizzo,' retrieved 9 February 2019: 
Carlson continues, ' ... "A considerable number of the boys and girls die within the first two or three years after beginning work," wrote Dr. Elizabeth Shapleigh, a Lawrence physician. "Thirtysix of every 100 of all men and women who work in the mills die before or by the time they are 25 years of age."

Cites Carlson (1983).

\subsection{Carlson (1983).}

Peter Carlson, Roughneck: The Life and Times of Big Bill Haywood, W. W. Norton, 1983, p. 161:

"A considerable number of the boys and girls die within the first two or three years after beginning work," wrote Dr. Elizabeth Shapleigh, a Lawrence physician. "Thirty-six of every 100 of all men and women who work in the mills die before or by the time they are 25 years of age."

Cites Cahn (1980).

\subsection{Cahn (1980).}

William Cahn, Lawrence, 1912: the Bread and Roses Strike, Pilgrim Press, 1980, p. 76 :

Reprints Cahn (1954).

\subsection{Cahn (1954).}

Bill Cahn, Mill Town, first edition, Cameron and Kahn, 1954, p. 80:

"A considerable number of the boys and girls die within the first two or three years after beginning work," stated Dr. Elizabeth Shapleigh of Lawrence. "Thirty-six out of every 100 of all men and women who work in the mill die before or by the time they are 25 years of age."

No specific citation; cites Ebert (1913) as a general reference. (See 1.6 above.) 


\section{It's epidemic.}

\subsection{Perlmutter (1999).}

Philip Perlmutter, Legacy of Hate: a short history of ethnic, religious, and racial prejudice in America, M. E. Sharpe, 1999, p. 129:

Conditions were so bad in one Massachusetts mill town that a doctor found "a considerable number of boys and girls die within the first year after beginning work. Thirty-six out of every 100 of all men and women who work in the mill die before or by the time they are twenty-five years of age."

Cites Krickus (1976).

\subsection{Krickus (1976).}

Richard Krickus, Pursuing the American Dream, Indiana University Press, 1976, p. 115:

Dr. Elizabeth Shapleigh of Lawrence found that "a considerable number of boys and girls die within the first year after beginning work. Thirty-six out of every 100 of all men and women who work in the mill die before or by the time they are 25 years of age."

Cites Cahn (1954). (See 2.4 above.)

\subsection{BGS (1985)}

Stewart Bird, Dan Georgakas, and Deborah Shaffer, Solidarity Forever, Lake View Press, 1985, p. 56:

At a time when the national life expectancy was nearly fifty years, over a third of all mill workers died before the age of twenty-six.

Cites Kornbluh (1972). (See 1.5 above.) 


\section{A Shapleigh's original article.}

Occupational diseases in the textile industry

By Elizabeth Shapleigh, M.D.

The New York Call-Sunday, December 29, 1912, p. 13.

It is clearly pointed out by all authorities on industrial disease that the mortality is high in all dusty trades, including the textile industry. Nevertheless, before measures of amelioration can be taken, there must be secured detailed, accurate information of the conditions under which the work is carried on and the degree of ill health among the workers. With this end in view, I will describe some of the insanitary conditions in the Lawrence textile mills and their effect on the workers.

The city of Lawrence, Mass., outranks every other city in the Union in the manufacture of woolen and worsted goods. Out of a total population of 85,892 , approximately one-half of the men and women over 14 years of age are employed in this one industry. This offers an exceptional opportunity to investigate industrial disease.

Data have been obtained by personal observation in the mills, from various public records and reports, and eminent medical authorities. The vital statistics tabulated in this paper are taken from the records of the city of Lawrence, Mass., for the years 1903-1911 inclusive.

The essential elements in the sanitary arrangements peculiar to textile mills are a proper regulation of the ventilation, the temperature and the humidity, besides a proper disposal of the fine organic dust generated during the process of cloth-making. When neglected, as they now are, these four factors combine to produce unhygienic surroundings, and markedly affect the health of the worker.

Let us consider first the high degree of humidity maintained in the weaving room. A certain amount of moisture is necessary in order to soften the sizing on the thread so that it may be more easily manipulated in the process of weaving. This sizing, by the way, adds to the weight and so is wrong from a moral point of view. Besides, the flocculent dust which it produces is inhaled and, therefore, harmful to the operative. To obtain the required humidity, steam is artificially introduced at regular intervals by steam jets near the ceiling. At times it is so excessive as to cause perceptible dampening of the clothing of the worker.

Added to this is the high temperature, kept at about $84 \mathrm{~F}$. in winter and frequently rising to $130 \mathrm{~F}$. and over on a hot summer day. It is easy to understand how, with garments saturated with perspiration and moisture, the 
workers upon leaving such an atmosphere and proceeding home on a cold winter evening become thorouhly [sic] chilled. This causes them to be especially susceptible to bronchitis, pulmonary complaints, and to rheumatism. Moreover, the hot, moist air is enervating and unfits one to bear fatigue. It is difficult to estimate the full effect, for neurasthenia, the bane of the overworked and underfed, does not leave a definite trace on the mortality records.

Furthermore, the ventilation is insufficient. A draft of air causes the thread to break. Consequently, the windows are rarely opened except in summer. From good authority we learn that the room is never ventilated after work hours.

All that has been said about heat and moisture in the weaving-room applies equally to the dye-house. There the moisture is so great that it condenses on the walls, floor, and even on the hair of the dyers. The constantly wet cement floors cause the bare or shoe-clad feet of the dyer to be always wet and cold, a predisposing cause of respiratory diease and rheumatism. The inhalation of the arsenical fumes from the aniline dye likewise has an injurious effect.

The fine particles of fiber thrown off in the process of carding and spinning are suspended in the air like a thick misty cloud, which obscures the vision. These particles settle on the hair and garments of the operatives. They fall on their face, cling to the eyebrows and fringe the nostrils, irritating the delicate mucus lining. In the carding-room this dust is excessive. It hangs on the machinery and drops from it in large masses, covering the floor.

This fine organic dust irritates the delicate membranes lining the nose, throat, larynx, and bronchial tubes. In the smaller bronchi and air cells of the lungs the dust induces a low form of inflammation, which ends in the transformation of the spongy substance of the lung into hard unyielding fibrous tissues quite unfitted for the purpose of respiration. This fibrotic lung disease is termed pneumokomosis. On microscopic examination of the sputum, fibers of the cotton or wool may be found.

The rate of mortality from pneumonia among weavers is 17.9 per cent, as compared with 12.6 per cent among spinners. Among dyers it is higher than that shown in any other room (18.7 per cent). Mortaility from tuberculosis is greater among spinners and combers. It is 27.2 per cent in the first and $331-3$ per cent in the latter, as compared with 18.4 per cent among weavers. The death rate from tuberculosis is also high among dyers. Another noteworthy fact is the high mortality from respiratory diseases, including pulmonary tuberculosis. According to the statistics it is 46.9 per cent among dyers and 
53.3 per cent among combers.

A study of the mortality from tuberculosis, pneumonia and from total causes of death of spinners, at specified age periods, discloses that 50 per cent of the deaths of spinners from tuberculosis occurs before the 25th year, and 75 per cent before the 35th year. Deaths from pneumonia occur at a much later age. Only 20 per cent occur before the 35th year and 40 per cent between the 56 th and 65 th years.

Of all those persons engaged in spinning as a trade, 36.6 per cent die before they have worked ten years. Out of a hundred deaths thirty-six die before they are 25 years of age, and fifty-two before they are 35 years of age. That is, over one-third die just as they attain maturity, and over one-half as they reach the most productive years. It is very rare that a spinner lives to be 70 years of age.

Among the various occupations carried on in the City of Lawrence, Mass., the one sowing the greatest mortality from tuberculosis is the textile industry; 27.1 per cent of all operatives die from infection by bacillus of tuberculosis. There have been 1,010 recorded deaths of textile operatives in the city during the last nine years (1903-1911) and 274 of them have been due to tuberculosis. Whereas from the twenty-one recorded deaths of manufacturers there has not been a single death from that disease. Mortality from tuberculosis in the professional class was 9.7 per cent, or only one-third of that among operatives. The farmers show a consumptive morality [sic] of four-fifths of 1 per cent, and the day laborer 12.8 per cent, while the skilled trades range between this low mortality on the one hand, and the high mortality among operatives.

Mortality from pneumonia is high among all classes of operatives, but rates the highest among the dyers (18.8 per cent). The death rate from the various forms of respiratory trouble show the lowest record among farmers, 2.6 per cent, and the highest among textile operatives, 41 per cent. Death from respiratory trouble occurs only one-third as often among textile manufacturers as among textile mill employes.

Philanthropists and social workers lay much stress on housing conditionspoor ventilation, dark rooms, crowded tenements - as causes of tuberculosis among the poorer portion of the working class. In comparing the mortality statistics of the unskilled laborer with that of the operatives, we find the longevity much greater. These two classes of workmen live in similar home environment, in the same poverty-stricken condition, yet only 12.8 per cent died from tuberculosis, and only 29.6 per cent from respiratory trouble. The mortality from consumption among day laborers, then, is only one-half that 
among mill operatives. Furthermore, the death rate from respiratory trouble is only 29.6 per cent, as compared with 41 per cent among operatives in general, and 53.3 per cent among the combers. It would be interesting and instructive to collect additional data along this line.

A study of the figures will show the average longevity in the most important occupations in the City of Lawrence, according to the mortality records of that city for the years 1903-1911, inclusive. Lawyers and clergymen head the list with an average length of life of 65.4 years. Manufacturers come next with a longevity of life of 58.5 years, and the farmer with 57 years. Operatives have the shortest life-span. From the mortality record of 1,010 operatives, the average length of life was found to be 39.6 years. The average longevity of the spinners is three and two-fifths years less, or 36 years. On an average, a spinner's life is twenty-two and one-half years shorter than that of his employer, the manufacturer.

Another significant fact is that the longevity of the laborer is considerably greater than that of the textile operative. From 373 deaths among laborers the average length of life was 47.6 years, while that of the operative is eight years less, and of the spinner eleven and three-fifths years less. Bear in mind that the former reference was made to the fact that although living in practically the same home environment the mortality from tuberculosis and respiratory disease was much less than that among textile operatives. The men and women in these various occupations lived and worked in the same city, subject to the same climate and the same atmospheric variations.

The report on the strike of the textile workers in Lawrence, Mass., in 1912, which was prepared under the direction of Charles P. Neill, Commissioner of Labor, shows that approximately 11.5 per cent of the total mill employes are under 18 years of age. Among the foreign population it is the custom for a boy or a girl to go to work in the mill as soon as possible after the 14th birthday. Many of these, when beginning work, suffer from a malaise known as "mill fever," the symptoms of which are nausea, vomiting, headache, and rise of temperature. Usually the indisposition lasts only two or three days. It is attributed to the inhalation of dust, the stifling atmosphere and the disagreeable odor of the oil.

From the mortality statistics we learn that a considerable number of these young boys and girls die within the first two or three years after beginning work. With very few exceptions, death is due to tuberculosis, pneumonia, or typhoid fever.

Data with regard to the consumptive mortality per 1,000 operatives could not be obtained, because of the inaccurate and incomplete mortality record 
of the city. For instance, a large number of women work in the mills, either before or after marriage, and contract tuberculosis and die. Because they are married their occupation is recorded as "at home" or "housewife." The significant fact that they have worked in the mill is lost and it becomes impossible to trace the true cause of their contracting the disease. Again, a number of young men and women who have been out of the mill, ill with tuberculosis for several month or years, are recorded as "at home." Here again their occupation is not recorded and the reason for their contracting consumption may not be attributed to the real cause. Again, in statistics of various trades and professions, the word "retired" is often used instead of stating the former occupation as well. This simple addition would facilitate matters, and permit of greater accuracy.

The high mortality in the textile industry can largely be averted by the introduction of a few simple devices. A careful and thorough regulation of the ventilation, humidity, and temperature must be insisted upon. It is a known fact that thought for the welfare of the worker is not considered in the regulation of these conditions. Temperature is maintained much higher, necessitating a greater degree of humidity in the weaving-rooms of this country than is permitted abroad. England and Germany have stringent laws requiring modern appliances about the machines, whereby the dust is carried off from the point of production by ventilating flues, hoods, shafts, fans, etc.

Introduction of these simple devices would make an appreciable difference in the mortality from tuberculosis and other respiratory diseases. It is hoped that in the near future the textile operatives in the United States may work under the same hygienic conditions as now exist abroad. 


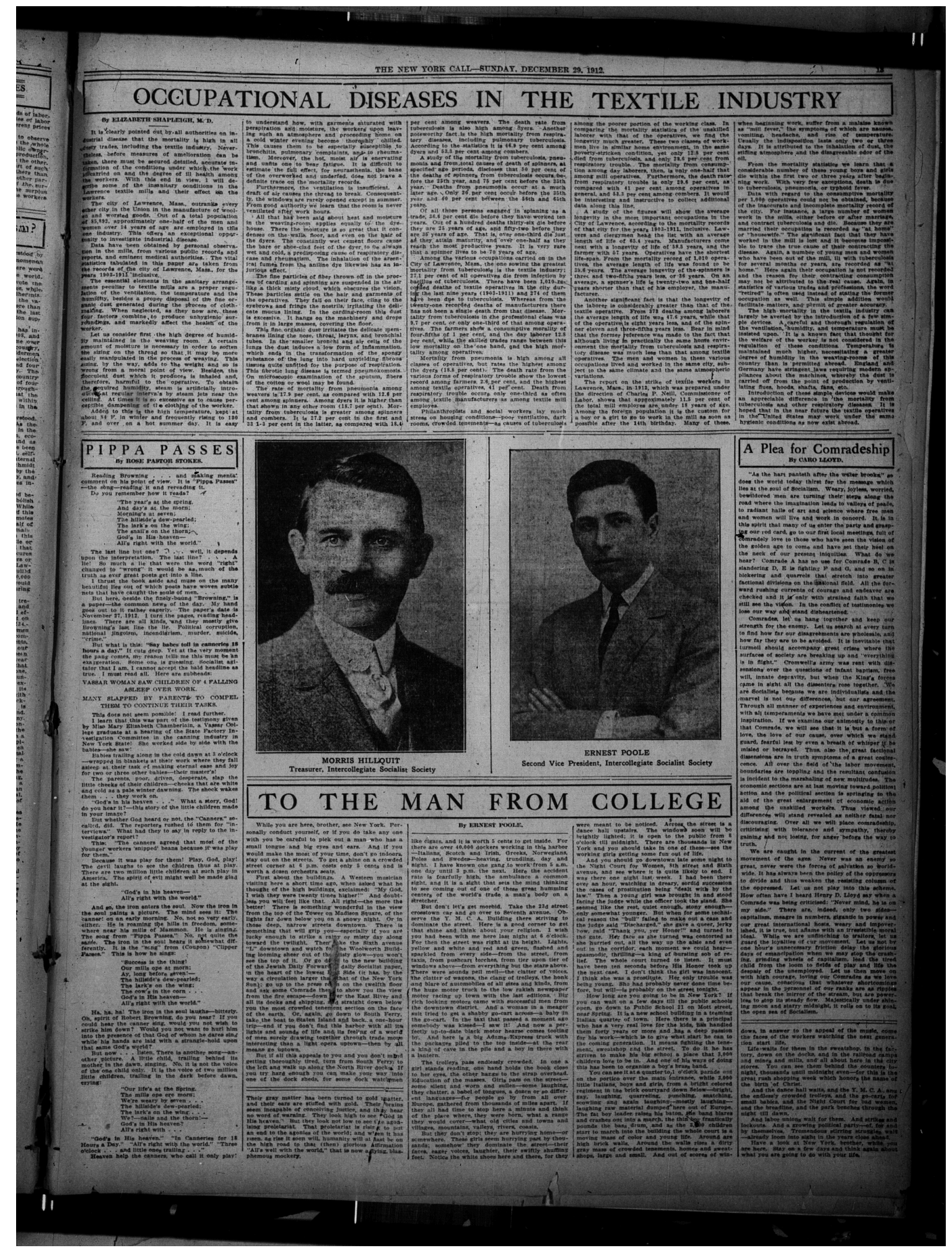




\section{B Elizabeth Rollins Shapleigh, 1876-1930.}

Elizabeth Rollins Shapleigh, born 24 February 1876, Lebanon, Maine; died 21 March 1930, Shanghai, China.

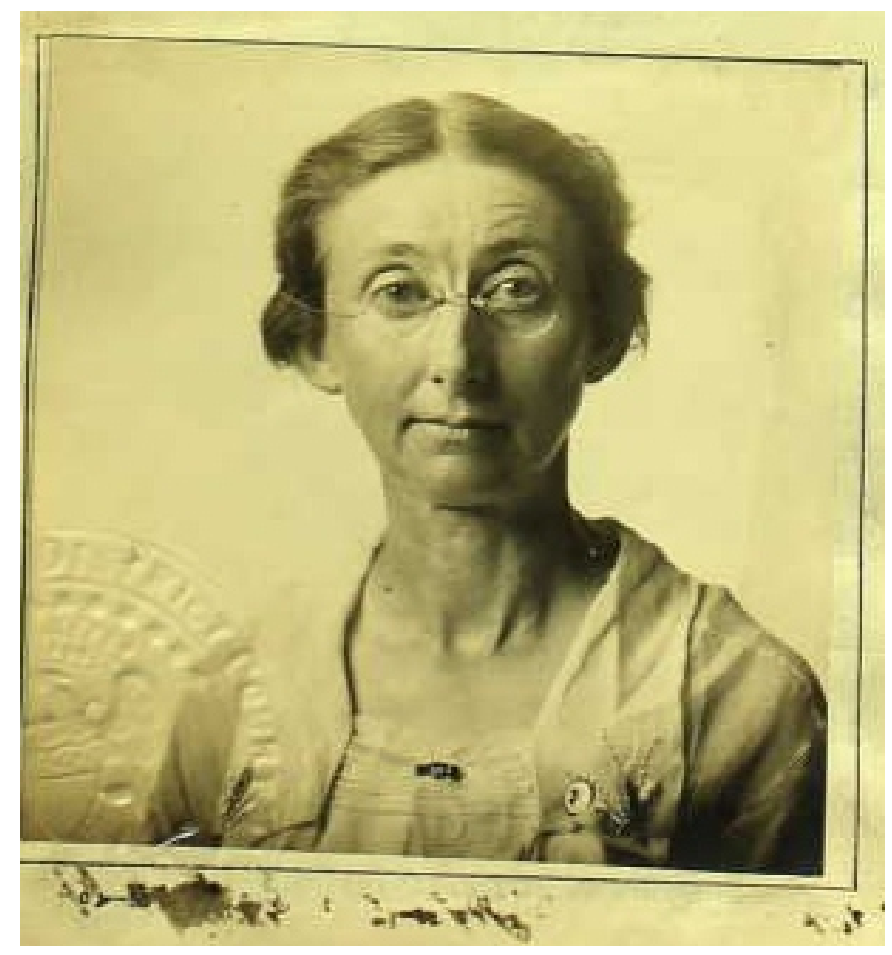

'Shanghai Hongkew Medical Dispensary,' F. Y. Pan, M.D., The China Medical Journal, vol. 44 (1930), p. 793:

The Hongkew General Dispensary (formerly known as the Swarthmore Dispensary) was started by Dr. Elizabeth Shapleigh in a small Chinese house on Tien Teh Road in November 1925 and was later moved to its present quarters at 173 Lin Ping Road in November 1928. Following the death of Dr. Shapleigh, the Hongkew General Dispensary was taken over by the Chinese Mission to Lepers on 1st April 1930.

The dispensary clinic differs from most other clinics in the city, in that it has only one class of patients. All are poor and quite unable to pay anything towards the cost of their treatment. 


\section{Acknowledgements}

It is a pleasure to acknowledge the help of Keegan Harris, Dexter Arnold, and staff members of the Lawrence History Center; the Lawrence Public Library; and Harvard's Widener Library. 